\title{
PAPER
}

\section{A study of persistent post-concussion symptoms in mild head trauma using positron emission tomography}

\author{
S H A Chen, D A Kareken, P S Fastenau, L E Trexler, G D Hutchins
}

J Neurol Neurosurg Psychiatry 2003;74:326-332

See end of article for authors' affiliations

.....................

Correspondence to: Dr S H Annabel Chen, Stanford School of Medicine, Radiology, Lucas MRS Imaging Center 1201 Welch Road, MC: 5488, Stanford, CA

94305, USA

annabel.chen@stanford.edu

Received

10 November 2001

In revised form

13 August 2002

Accepted

12 September 2002
Background: Complaints of persistent cognitive deficits following mild head trauma are often uncorroborated by structural brain imaging and neuropsychological examination.

Objective: To investigate, using positron emission tomography (PET), the in vivo changes in regional cerebral uptake of $2-\left[{ }^{18} \mathrm{~F}\right]$ fluoro-2-deoxy-D-glucose (FDG) and regional cerebral blood flow (rCBF) in patients with persistent symptoms following mild head trauma.

Methods: Five patients with mild head trauma and five age and education matched healthy controls were imaged using FDG-PET to measure differences in resting regional cerebral glucose metabolism. Oxygen-15 labelled water $\left(\mathrm{H}_{2}{ }^{15} \mathrm{O}\right)$-PET was also used to measure group differences in $\mathrm{rCBF}$ changes during a spatial working memory task. In addition, neuropsychological testing and self report of dysexecutive function and post-concussion symptoms were acquired to characterise the sample.

Results: There was no difference between patients and controls in normalised regional cerebral FDG uptake in the resting state in frontal and temporal regions selected a priori. However, during the spatial working memory task, patients had a smaller increase in rCBF than controls in the right prefrontal cortex.

Conclusions: Persistent post-concussive symptoms may not be associated with resting state hypometabolism. A cognitive challenge may be necessary to detect cerebral changes associated with mild head trauma.
$\mathrm{P}$ ost-concussion symptoms are among the most common complaints after mild to moderate head injury. ${ }^{1}$ These symptoms include dizziness, headache, sensory sensitivities, impaired attention, poor memory, and executive dysfunction. Irritability, depression, nervousness, discouragement, and anger are also prominent. ${ }^{2}$ Most often, objectively measured cognitive functions in most subjects with mild head trauma are not significantly different from normal controls at three months post-injury. ${ }^{34}$ Subjective complaints, however, can continue beyond three months. The diagnosis of post-concussion symptoms is largely dependent on the patient's and family members' report, with limited corroborative evidence from neuropsychological testing, physical examination, and neuroanatomical imaging such as computed tomography (CT) and structural magnetic resonance imaging (MRI). The lack of objective findings thus makes it difficult to attribute symptoms to documented neuropathological causes, at least in the chronic stage.

Functional imaging in mild head trauma may be more sensitive to physiological defects. For example, single photon emission computed tomography (SPECT) in patients with mild to moderate head trauma has been reported to show a larger number of abnormalities than $\mathrm{CT}^{5-7}$ or MRI. ${ }^{8}{ }^{9}$ However, the lack of large, well controlled studies prompted the therapeutics and technology assessment subcommittee of the American Academy of Neurology ${ }^{10}$ to caution against the diagnostic use of SPECT for mild head trauma. Positron emission tomography (PET) using 2-[F-18]fluoro-2-deoxyglucose (FDG) in head injured persons with normal neuroanatomical scans has also indicated hypometabolism in frontal and temporal brain regions, ${ }^{11-13}$ with which deficient neuropsychological performance and post-concussion symptoms can be correlated. ${ }^{13}$ More recently, resting state FDG uptake in patients with late whiplash syndrome and suspected brain injury showed hypometabolism in the parieto-occipital regions ${ }^{14}$; however, this finding was not replicated by Bicik et $a l,{ }^{15}$ who instead found hypometabolism in the frontal regions that correlated with depression. Radanov et al also failed to show correlations between neuropsychological performance and FDG uptake in late whiplash patients. ${ }^{16}$ Studies with functional MRI ${ }^{17}$ have shown that working memory evoked activation differed between controls and patients one month after mild head injury.

These studies suggest that functional neuroimaging may detect subtle changes in cerebral physiology. However, not all studies used matched controls, and some included patients who were less than three months post-injury. In this study we investigated resting state regional cerebral metabolism and changes in regional cerebral blood flow (rCBF) during a spatial working memory task in patients with mild head trauma and persistent post-concussion symptoms. The results were then compared with an age and education matched control group. We hypothesised that people with persistent symptoms beyond three months after mild head trauma would have lower FDG uptake in the temporal and frontal brain regions, and a smaller change in $\mathrm{rCBF}$ while performing a spatial working memory task.

\section{METHODS}

\section{Participants}

Five patients and five healthy controls were matched case by case for sex (three women and two men in each group), age (patients 34.4 (11.9) years (mean (SD)); controls 34.2 (11.6) years; $\mathrm{p}=0.98$ ), handedness (one left handed in each group), and education (patients 14.4 (1.8) years; controls 14.2 (1.5) years; $p=0.85)$. Controls were excluded if they had a history of neurological and psychiatric diagnoses, including concussion and learning disability.

Abbreviations: CVLT, California verbal learning test; FLOPS, frontal lobe personality scale; PCSC, postconcussion syndrome checklist; ROI, region of interest 
Table 1 Patient injury characteristics

\begin{tabular}{|c|c|c|c|c|c|c|c|}
\hline Patient & $\begin{array}{l}\text { Age } \\
\text { (years) }\end{array}$ & Sex & Type of injury & Litigation & $\begin{array}{l}\text { Time since injury } \\
\text { (months) }\end{array}$ & $\begin{array}{l}\text { LOC reported } \\
\text { (minutes) }\end{array}$ & $\begin{array}{l}\text { Estimated PTA } \\
\text { (hours) }\end{array}$ \\
\hline P01 & 42 & $F$ & Blunt object & No* & 35 & 0.00 & 1.00 \\
\hline P02 & 48 & $\mathrm{~F}$ & Fall & No & 10 & 0.00 & 0.30 \\
\hline $\mathrm{PO} 3$ & 23 & M & Blunt object & No* & 14 & 0.00 & 0.00 \\
\hline P04 & 38 & $M$ & Blunt object & No & 5 & 0.50 & 3.00 \\
\hline P05 & 21 & $\mathrm{~F}$ & Fall & No & 19 & 2.00 & 0.03 \\
\hline Mean & 34.4 & & & & 16.60 & 0.50 & 0.87 \\
\hline SD & 11.89 & & & & 11.50 & 0.87 & 1.26 \\
\hline P01 & \multicolumn{7}{|c|}{$\begin{array}{l}\text { Injury description } \\
\text { to-occipital region by a falling } 500 \mathrm{lb} \text { barrel with no loss of } \\
\text { and had headaches the next day. She was seen at the }\end{array}$} \\
\hline P02 & \multicolumn{7}{|c|}{$\begin{array}{l}\text { P02 slipped and fell while getting out of the bathtub at home and struck the back of her head on a } \\
\text { wooden door, and broke her right shoulder, with no loss of consciousness. She developed nausea } \\
\text { and dizziness for a week but was not admitted to hospital. }\end{array}$} \\
\hline P03 & \multicolumn{7}{|c|}{$\begin{array}{l}\text { PO3 was struck in the forehead by a steel cage at work with no loss of consciousness. He } \\
\text { developed nausea and vomiting with severe headaches the next day, where he went to the } \\
\text { emergency room and was discharged. }\end{array}$} \\
\hline P04 & \multicolumn{7}{|c|}{$\begin{array}{l}\text { PO4 was struck in the face by a large sheet of corrugated steel decking. He lost consciousness for } \\
\text { about } 30 \text { seconds on impact, and on two further occasions before the emergency team. He was } \\
\text { disoriented and had an impact seizure. He underwent facial surgery and was in hospital for two days. }\end{array}$} \\
\hline P05 & \multicolumn{7}{|c|}{$\begin{array}{l}\text { PO5 tripped and fell on doorsteps at home, hitting her forehead. She was briefly unconscious for } \\
1-2 \text { minutes and developed headaches with no disorientation. She was seen by her family doctor } \\
\text { a few days later. }\end{array}$} \\
\hline
\end{tabular}

Patients were diagnosed with mild head trauma using the American Congress of Rehabilitation Medicine definition ${ }^{18}$; diagnosis of post-concussion symptoms was based on the Diagnostic and Statistical Manual of Mental Disorders, 4th edition (DSM-IV) research criteria. ${ }^{19}$ Patients were excluded if there was a history of axis-I psychiatric disorders, learning disability, or previous head trauma, and they were less than three months post-injury (16.6 (11.5) months). None had lesions on clinical CT or MRI, and none showed signs of malingered memory loss on the digit memory test. ${ }^{20}$ Table 1 shows the injury characteristics of the patients.

The symptom checklist 90 -revised ${ }^{21}$ was also administered to measure psychopathological symptoms of psychological distress in patients and controls. There was no significant difference between the two groups for depression $(p>0.70)$, anxiety $(p>0.37)$, or positive symptoms reported $(p>0.33)$, and no participants were excluded from the study on the basis of psychological functioning.

\section{Measures and procedure}

\section{Neuropsychological and symptom complaint measures}

Standardised neuropsychological tests were administered to assess attention, memory, executive function, and visual perception/constructional praxis (table 2). To facilitate comparisons, test scores were transformed to z scores using each test's respective normative sample. All scores were converted such that higher, positive scores reflect better test performance. Then, to reduce the data and to control for type I error, the $\mathrm{z}$ scores of groups of tests were averaged to create eight rationally derived neuropsychological composite scores. In the protected $\mathrm{F}$ tests we found that the control group performed significantly better than the patient group $(t=-2.74$; $\mathrm{p}<0.03)$. This finding was largely driven by the significantly higher recognition scores of the California verbal learning test (CVLT) in the controls $(t=-5.52 ; \mathrm{p}<0.01$; see table 2$)$. There was also a tendency $(p<0.06)$ for patients to have slower psychomotor speed than the controls. Nevertheless, the patients were significantly different on some individual measures, as reflected by univariate $t$ tests (omission and commission errors on the continuous performance test, memory for oral narrative on the Wechsler memory scale-3 logical memory passages). Further, the patient group's performance on the CVLT total learning variable can be considered to be very mildly defective (that is, close to -1.5 SD below the standardisation sample's mean).

Post-concussion symptoms were quantified using the postconcussion syndrome checklist (PCSC). ${ }^{36}$ Such symptoms were both more frequent $(t=2.33, \mathrm{p}<0.05)$ and more intense $(t=2.60, \mathrm{p}<0.03)$ in the patients than in the controls. Neurobehavioural features of frontal lobe injury were quantified using self report forms of the frontal lobe personality scale (FLOPS), ${ }^{37}$ on which the patient and control groups did not differ significantly (apathy: $t=0.84, \mathrm{p}<0.43$; disinhibition: $t=0.56, \mathrm{p}<0.59$; executive dysfunction: $t=1.13, \mathrm{p}<0.29$ ).

\section{Positron emission tomography}

Participants were imaged in a Siemens 951/31R whole body PET tomograph (6 mm FWHM intrinsic resolution; Siemens Inc, Hoffman Estates, Illinois, USA) in a supine position, with the head aligned approximately $\mathrm{l} \mathrm{cm}$ below the cantomeatal line. A Dermaform ${ }^{\circledR}$ pillow and a hook and loop strap were used to secure the position of the head. Attenuation was corrected by a transmission scan using three internal rod sources before scanning. Dynamic imaging sequences were used within each session. For the resting state study, an intravenous bolus of $10 \mathrm{mCi}$ of FDG was injected. Participants were kept awake during the 60 minute scan by a simple tone monitoring task (pressing a button when a tone sounded, without requiring a quick reaction time). Lights were dimmed during scanning, and the participants were instructed to remain still, eyes open, and ears unplugged.

During the rCBF working memory study, participants performed the Jonides spatial working memory $\operatorname{task}^{38}$ (fig 1) after an injection of $\mathrm{H}_{2}{ }^{15} \mathrm{O}$. Inverted mirror goggles were used to visualise the task stimuli directly behind the participants as presented on a $\mathrm{PC}$ computer.

A single bolus of $50 \mathrm{mCi} \mathrm{H}_{2}{ }^{15} \mathrm{O}$ was injected before each of two three-minute scans. The memory condition was administered during the first injection and the control condition during the second. Participants were given practice sessions before scanning to become comfortable with the task requirements. 
Table 2 Neuropsychological test scores

\begin{tabular}{|c|c|c|c|c|c|c|}
\hline \multirow[b]{2}{*}{ Neuropsychological domains } & \multicolumn{2}{|c|}{ Patients $(n=5)$} & \multicolumn{2}{|c|}{ Controls $(n=5)$} & \multicolumn{2}{|c|}{ Statistics } \\
\hline & Mean & SD & Mean & SD & $t$ & $\mathrm{p}$ \\
\hline Working memory (z scores) & -0.28 & 0.70 & -0.11 & 0.87 & -0.35 & 0.74 \\
\hline $\mathrm{ACT}^{1}$ (9s z scores for $\mathrm{n}$ correct) & -0.20 & 1.21 & -0.19 & 1.47 & -0.01 & 0.99 \\
\hline$A C T^{1}$ (18s z scores for $n$ correct) & -0.52 & 1.08 & -0.22 & 1.37 & -0.39 & 0.71 \\
\hline $\mathrm{ACT}^{1}$ (36s z scores for $\mathrm{n}$ correct) & -0.83 & 1.07 & -0.15 & 2.19 & -0.63 & 0.69 \\
\hline Digit span backwards ${ }^{2}$ (z scores) & -0.44 & 1.01 & -0.81 & 0.50 & 0.74 & 0.49 \\
\hline Visual span backwards ${ }^{2}$ (age SS) & 9.60 & 2.88 & 11.60 & 2.07 & -1.26 & 0.24 \\
\hline Letter-number sequencing ${ }^{3}$ (age SS) & 9.00 & 2.12 & 12.20 & 4.66 & -1.40 & 0.22 \\
\hline PASAT $^{4}$ ( $z$ scores for errors) & 0.50 & 1.14 & -0.06 & 1.56 & 0.64 & 0.55 \\
\hline Psychomotor speed (z scores) & -0.36 & 0.83 & 0.65 & 0.60 & -2.21 & 0.06 \\
\hline Digit symbol $^{3}$ (age SS) & 8.80 & 3.19 & 12.40 & 2.41 & -2.01 & 0.08 \\
\hline Symbol search ${ }^{3}$ (age SS) & 9.80 & 2.59 & 11.80 & 2.28 & -1.30 & 0.23 \\
\hline Trails $A^{5}$ ( $t$ scores) & 44.00 & 10.54 & 55.60 & 16.41 & -1.33 & 0.54 \\
\hline Vigilance (z scores) & -1.13 & 0.51 & -0.52 & 0.67 & -1.64 & 0.14 \\
\hline $\mathrm{CPT}^{6}$ (z scores for omission errors) & -1.24 & 0.61 & -0.13 & 0.47 & -3.20 & 0.01 \\
\hline $\mathrm{CPT}^{6}$ (z scores for hit reaction time, standard error) & -1.02 & 0.77 & -0.90 & 0.95 & -0.22 & 0.83 \\
\hline Immediate memory (z scores) & -0.96 & 0.44 & -0.07 & 1.05 & -1.76 & 0.12 \\
\hline $\mathrm{CVLT}^{7}$ (t scores for total correct) & 36.40 & 7.37 & 48.00 & 11.73 & -1.87 & 0.11 \\
\hline $\mathrm{CFT}^{8}$ immediate (age SS) & 9.60 & 2.41 & 9.40 & 3.36 & 0.11 & 0.92 \\
\hline $\mathrm{CVMT}^{9}$ discrimination (z scores) & -1.32 & 0.91 & 0.22 & 2.06 & -1.53 & 0.16 \\
\hline Logical memory $\mathrm{I}^{2}$ (age SS) & 7.80 & 2.17 & 11.00 & 1.41 & -2.53 & 0.04 \\
\hline Delayed memory (z scores) & -0.51 & 0.68 & 0.32 & 1.31 & -1.27 & 0.24 \\
\hline $\mathrm{CVLT}^{7}$ long delay (z scores) & -1.14 & 0.88 & 0.48 & 1.37 & -2.23 & 0.06 \\
\hline $\mathrm{CFT}^{8}$ delayed (age SS) & 9.80 & 1.79 & 10.00 & 3.74 & -0.11 & 0.92 \\
\hline Logical memory $\|^{2}$ (age SS) & 9.00 & 2.83 & $13.25^{*}$ & $2.63^{*}$ & -2.31 & 0.05 \\
\hline Recognition memory (z scores) & -1.56 & 0.52 & 0.03 & 1.19 & -2.74 & 0.03 \\
\hline $\mathrm{CVLT}^{7}$ recognition (z scores) & -3.20 & 1.30 & 0.20 & 0.45 & -5.52 & 0.01 \\
\hline $\mathrm{CVMT}^{9}$ recognition (z scores) & -0.93 & 0.47 & 0.50 & 2.45 & -1.28 & 0.26 \\
\hline $\mathrm{ECFT}^{10}$ (age SS) & 8.40 & 2.70 & 8.20 & 3.03 & 0.11 & 0.92 \\
\hline Executive function (z scores) & -0.10 & 0.66 & 0.32 & 0.89 & -0.84 & 0.43 \\
\hline $\mathrm{CPT}^{6}$ (t scores for commission errors) & 45.50 & 6.67 & 59.88 & 4.62 & -3.96 & 0.00 \\
\hline COWAT $^{11}$ (z scores) & -0.56 & 0.67 & -0.01 & 1.33 & -0.83 & 0.44 \\
\hline Trails $B^{5}$ ( $t$ scores) & 49.40 & 10.14 & 49.20 & 12.68 & 0.03 & 0.98 \\
\hline WCST $^{12}$ ( $t$ scores for perseverative responses) & 54.20 & 16.30 & 54.40 & 16.73 & -0.02 & 0.99 \\
\hline $\mathrm{WCST}^{12}$ (t scores for errors) & 50.60 & 9.07 & 54.40 & 13.01 & -0.54 & 0.61 \\
\hline Visual-spatial skills (z scores) & 0.43 & 1.17 & -0.17 & 0.58 & 1.02 & 0.34 \\
\hline Block design ${ }^{3}$ (age SS) & 12.20 & 3.03 & 9.80 & 2.17 & 1.44 & 0.19 \\
\hline $\mathrm{CFT}^{8}$ copy (z scores) & 0.16 & 1.18 & -0.88 & 1.18 & 1.40 & 0.20 \\
\hline \multicolumn{7}{|c|}{ 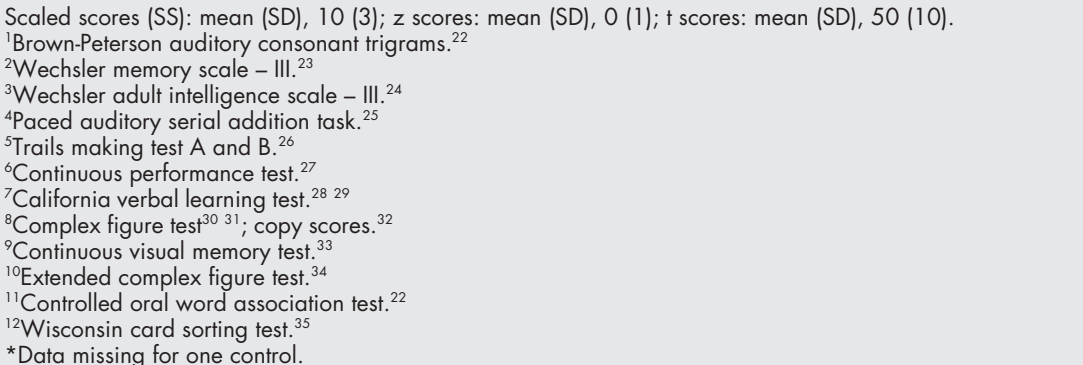 } \\
\hline
\end{tabular}

rCBF changes in the perception control were then subtracted from those in the memory condition. Because the perception control was perceptually similar to the memory condition, the result of the subtraction is $\mathrm{rCBF}$ change attributable to spatial working memory.

\section{Brain imaging}

Anatomical MRIs were acquired on a GE Signa, 1.5 Tesla scanner (General Electric Co, Waukeshi, Wisconsin, USA) to permit PET-MRI coregistration. One whole brain image series was collected using axial gradient echo $\mathrm{T}_{1}$ image (time of repetition $=24 \mathrm{~ms}$, time of echo $=5 \mathrm{~ms}$ (minimum), flip angle $=30^{\circ}$, field of view $=24 \mathrm{~cm}$, slice thickness $=1.2 \mathrm{~mm}$, $256 \times 128$ matrix, 1 nex) .

\section{Image analysis}

Resting state study

In-house software was used to analyse PET images. Activity within each region of interest (ROI) was averaged and normalised to the calcarine cortex. ROIs in the frontal and temporal regions were chosen to be the focus of analysis and comparison as these are most likely to be damaged in head trauma. Neuroanatomical landmarks were used to identify the ROIs with the aid of a neuroanatomical reference. ${ }^{39}$

\section{Working memory study}

The University of Michigan statistical analysis for PET activation software, V3.0 (Minoshima and Koeppe), was used to transform, group, and subtract the activation PET volumes 

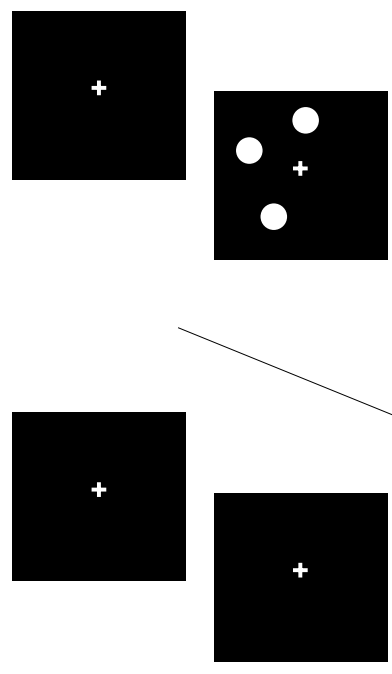

Perceptual control
Memory condition
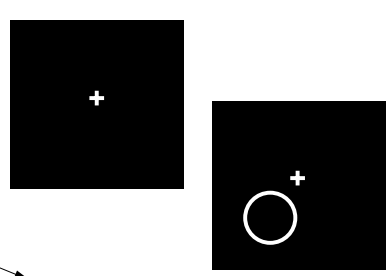

$$
\text { Time }
$$
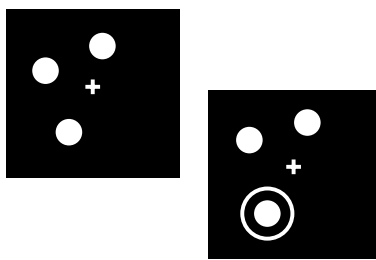

Figure 1 Spatial working memory task, adapted from Jonides et al (1993). ${ }^{38}$ The upper part of the figure illustrates the events in the "memory" condition of the experiment. Participants began by fixating on a cross in the centre of the screen for 500 ms. The cross was then supplemented by three dots appearing on the circumference of an imaginary circle, centered on the cross. The dots remained in view for $200 \mathrm{~ms}$ (too short an interval to permit a successful saccade to the dots on average), following which the fixation cross continued to appear for a retention interval of $3000 \mathrm{~ms}$. This was followed by a probe for location memory, which consisted of a circle that surrounded the location of one of the previous dots on half of the trials. The probe circle was presented for $1500 \mathrm{~ms}$. During this interval, participants pressed one of two response buttons to indicate if the probe marked the location of a dot. The probe circle was either centred directly over the previous location of a dot, or missed the nearest dot location by $15-40^{\circ}$. The lower part of the figure shows the events on each trial of the perception condition. Trials again begin with a fixation cross, which remained in view for 3500 ms (the duration of the fixation plus retention intervals in the memory condition). This was followed by three dots presented for about $200 \mathrm{~ms}$, followed immediately by an interval of $1500 \mathrm{~ms}$, during which the three dots and probe circle were presented simultaneously. As in the memory condition, participants press a response button to indicate whether or not the probe encircled a dot.

stereotactically, normalising individual pixel counts by average whole brain counts. The perception condition was subtracted from the memory condition, and $\mathrm{z}$ map images were calculated separately for both patients and controls. A statistical threshold of $z \geqslant 3.0$ ( $p \leqslant 0.001$, one tailed) was used to establish significance of activation..$^{40}$

Two approaches were used in analysing the effects of working memory between the groups. In the first approach, the regions significantly activated in the control group's $\mathrm{z}$ map image (thresholded at $\mathrm{z}>3.0$ ) were used as the ROIs for analyses of differences between groups. In addition, the spatial distribution of regions activated for both patient and control groups were compared by quantifying the three dimensional differences between regions of activation with the formula:

$$
\operatorname{diff}_{m m}=\sqrt{ }\left(x_{c}-x_{p}\right)^{2}-\left(y_{c}-y_{p}\right)^{2}-\left(z_{c}-z_{p}\right)^{2}
$$

where $\mathrm{x}, \mathrm{y}$, and $\mathrm{z}$ are Talairach coordinates, ${ }^{41}$ and the subscripts $\mathrm{c}$ and $\mathrm{p}$ represent controls and patients, respectively. For the second approach, regions that showed significant activation $(z>3.0)$ in the healthy controls studied by Jonides and colleagues $^{38}$ were used as the ROIs for analyses of differences between groups.
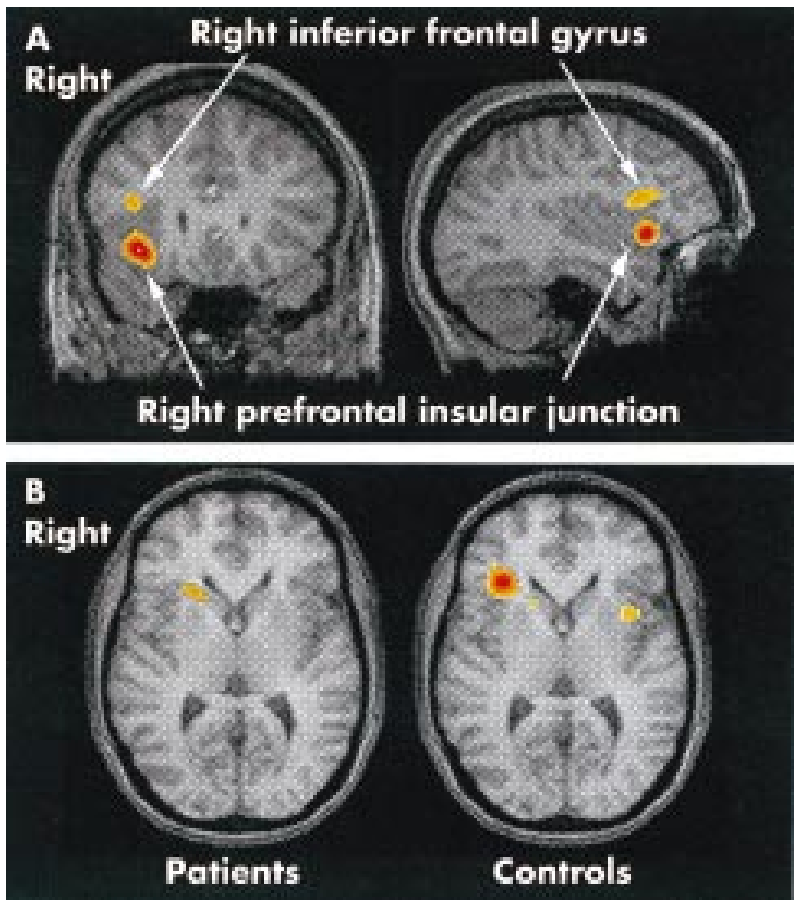

Figure 2 (A) Change in regional cerebral blood flow (activation) during spatial working memory task in healthy controls overlaid on reference magnetic resonance imaging (MRI). Statistical threshold was set at $z>3.0$. (B) Change in regional cerebral blood flow (activation) during spatial working memory task in patients (left) compared with healthy controls (right) overlaid on reference MRI (horizontal plane). Statistical display threshold, $z \geqslant 2.5$. Centroid of activation on the right prefrontal region is based on patient's region of activation $[-24,19,4]$.

\section{RESULTS}

\section{Resting state study}

There were no significant differences in normalised FDG uptake between patients and controls during the resting state in the ROIs investigated $(\mathrm{p}>0.10$; mean effect size $=0.21$ ). Thus, for cortical regions most likely to be injured in head trauma, the patients had the same range of normalised resting glucose metabolism as the healthy controls. A post hoc analysis using an ROI based on the significant activated centroid (right inferior frontal gyrus) in the working memory task (see below) also did not show the groups to be significantly different $(t=2.78 ; \mathrm{p}=0.85)$.

\section{Working memory study}

For the working memory task, accuracy scores of the perception condition showed a statistical trend, with patients scoring slightly lower than controls: 24.0 (1.9) v 26.6 (3.1) (mean $(\mathrm{SD})), t=1.59, \mathrm{p}=0.09$. Accuracy scores for the memory condition were not significantly different between patients and controls: $16.6(9.4) v 18.2(10.6) ; t=0.24, \mathrm{p}=0.41$. There was no statistical difference in perception condition reaction times between patients and controls (0.32 (0.59) s $v 0.39$ $(0.44) \mathrm{s} ; t=0.75, \mathrm{p}=0.23)$, nor was there a between group difference in reaction times for the memory condition (patients: $0.32(0.50)$ s; controls: 0.25 (0.69) s; $t=0.86, p=$ $0.20)$.

The z map image in the healthy controls produced two significant centroids of activation in the right prefrontal regions: the right prefrontal-insular junction (Talairach coordinates, $[-30,23,2], z=4.5)$ and the right inferior frontal gyrus (Talairach coordinates, [-33, 21, 22], z = 3.7; fig 2A, table 3). One significant centroid of activation was found for the patients in the right prefrontal-insular junction (Talairach coordinates, $[-24,19,4], z=3.0$; fig $2 B$ ), the locus of which 
Table 3 Change in regional cerebral blood flow evoked during spatial working memory task, identified from healthy control group $z$ map image

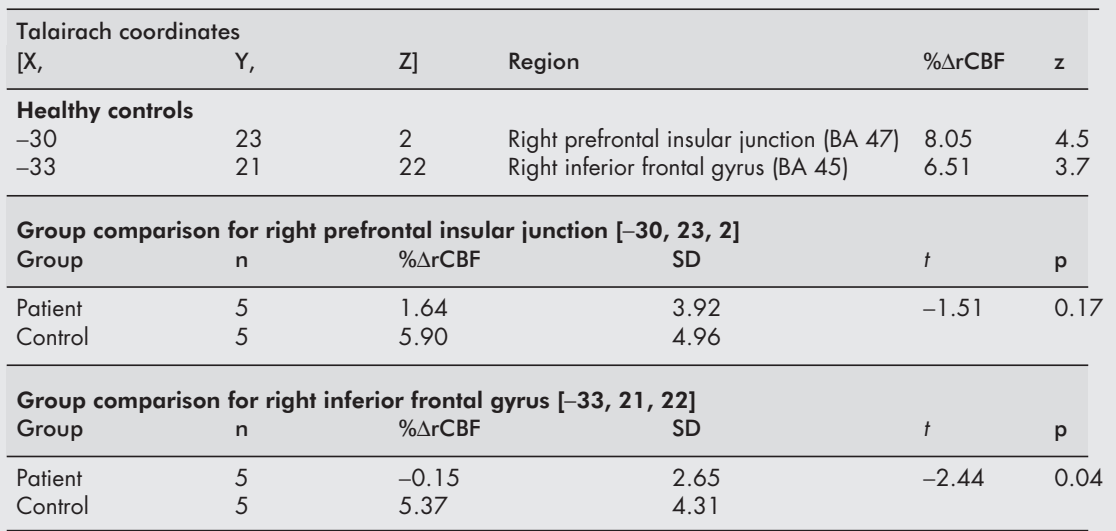

$X$ is left $(+)$, right $(-)$ of midline; $Y$ is anterior $(+)$, posterior $(-)$ to the anterior commissure; $Z$ is superior $(+)$, inferior $(-)$ to the anterior commissure-posterior commissure line.

$\mathrm{rCBF}$, regional cerebral blood flow.

was $7.5 \mathrm{~mm}$ in three dimensional space from the same region in the control sample. This spatial difference is within the reconstructed resolution of the PET images, and is therefore likely to be the same region in both groups.

$t$ Test analyses of the ROIs identified from the control group's z map showed no significant difference in the per cent change in $\mathrm{rCBF}$ between the groups for the right prefrontal insular junction: Talairach coordinates, $[-30,23,2](\mathrm{p}>0.17)$. However, patients had a smaller percentage change in $\mathrm{rCBF}$ than controls in the right inferior frontal gyrus: Talairach coordinates, $[-33,21,22](p<0.04)$ (fig 3$)$. Analysis of the

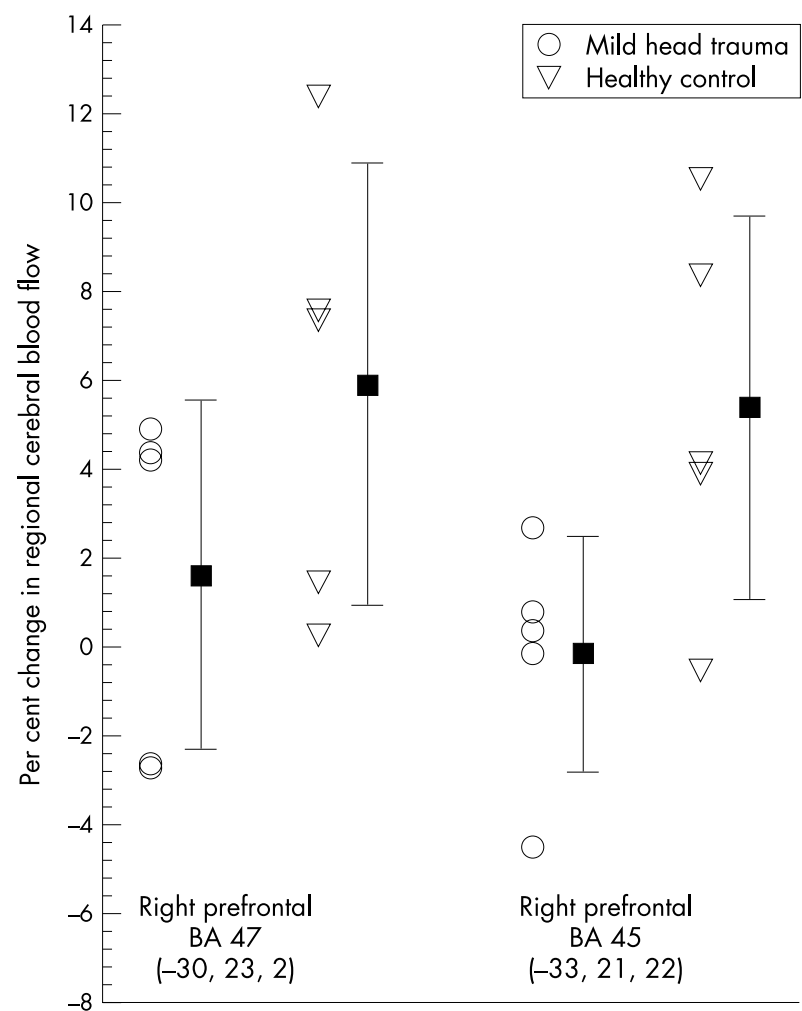

Figure 3 Distribution of per cent change in regional cerebral blood flow evoked during spatial working memory task within primary regions of interest in patients and healthy controls. Error bars represent one standard deviation.
ROIs identified by Jonides and colleagues ${ }^{38}$ revealed no significant differences between groups $(\mathrm{p}>0.10)$.

\section{DISCUSSION}

\section{Resting state study}

Our study did not show that patients with persistent symptoms of mild head trauma have lower resting FDG uptake than carefully matched healthy controls in the anterior temporal and frontal brain regions. This finding is contrary to that of Otte and colleagues, ${ }^{14}$ who found hypometabolism in the parieto-occipital regions of six whiplash patients compared with 12 normal controls. These investigators hypothesised that parieto-occipital hypometabolism may be caused by activation of nociceptive afferent nerves from the upper cervical spine. However, post hoc analysis of the parietooccipital regions in our subjects showed no significant differences $(p>0.50)$.

In a later study by Bicik and colleagues ${ }^{15}$ using FDG-PET in 13 whiplash patients and 16 controls, statistical parametric mapping revealed hypometabolism in frontopolar regions, lateral temporal cortex, and putamen, although hypometabolism in the frontopolar regions was correlated with scores on the Beck depression inventory. They also did not find differences in parieto-occipital regions when it was specifically examined. Rather, hypometabolism and cortical thickness measured on MRI were correlated, suggesting partial volume effects. Our non-significant differences in FDG uptake between controls and patients are consistent with the findings of Bicik et al, ${ }^{15}$ particularly insofar as we found no between-group differences in depression on the SCL-90-R-that is, if hypometabolism is indeed related to depression, as other studies have also found, ${ }^{42-48}$ then lack of differences in cerebral metabolism between our groups would be expected. Had depression been more prominent in the post-concussion symptoms sample, significant group differences might have emerged.

\section{Working memory study}

FDG uptake following mild head trauma has been investigated in three other studies while the patients performed sustained attention tasks. ${ }^{11-13}$ Significant differences were reported between patients and controls. Our findings were less dramatic for the working memory task during the $\mathrm{H}_{2}{ }^{15} \mathrm{O}$ study, but partially supported our hypothesis that patients would have a smaller increase in working memory induced rCBF in the right prefrontal brain regions than healthy controls. Using ROIs derived from the healthy controls' activation map, there 
was no group difference in activation in the right prefrontalinsular junction $[-30,23,2]$. While the patients did not activate this area above the threshold, they had a smaller, subthreshold activation within $7.5 \mathrm{~mm}$ of the controls' right prefrontal insular junction region, and within $12.5 \mathrm{~mm}$ of Jonides' right prefrontal region centroid $[-35,19,-2] .{ }^{38}$ Thus patients appeared to activate a similar region during the working memory task, albeit at a lower threshold. Nevertheless, the patients did have a slightly smaller working memory evoked rCBF increase in the right inferior frontal gyrus $[-33,21,22]$.

These findings are consistent with a recent functional MRI study in mild head trauma, ${ }^{17}$ in which McAllister and colleagues found working memory activation differences in 12 patients and 11 healthy controls in six cortical regions (bilateral middle frontal, bilateral medial parietal, right lateral parietal, and left superior parietal). Their patients performed an $n$-back task of two difficulty levels (1-back and 2-back) with 0 -back as the control condition. Patients showed less intense activation in similar regions than controls when performing the l-back task. But the patients had significantly more regions of activation and of increased intensity when performing the 2-back compared with the 1-back task. The authors suggested task difficulty as an explanation for the differences in the activation maps. Our study had a relatively simple working memory task analogous to their l-back task, and one that did not evoke performance differences between patients and controls. However, McAllister and colleagues ${ }^{17}$ studied their patients at the acute stage of six to 35 days posttrauma, during which changes might more clearly be expected.

\section{Limitations}

Our findings are not without limitations. The study has a relatively small sample (five patients and five carefully matched controls) and power is an important consideration. However, the mean effect size for the a priori ROIs in the resting state study was 0.21 and extremely small. Thus unrealistically large samples (more than 300 per group) would be needed to identify group abnormalities. Resting FDG appears insensitive to gross abnormalities in key brain regions in patients with mild injuries and persistent complaints.

Our small sample may also not be generalisable to the larger population of mild head trauma, as it was composed of falls and blunt injuries rather than the more common automotive accidents. That said, however, the group is relatively homogeneous in terms of injury mechanism, and each control was carefully selected to match the patient's demographics. A limitation of the working memory study was the absence of a counterbalanced order of condition presentation. Thus we cannot rule out the presence of uncontrolled carry over effects from one condition to the next, although this is less likely to affect a difference between groups treated in the same manner.

Finally, the patients were relatively free of cognitive impairment as reflected by neuropsychological test performance, both in absolute level and in comparison with the controls. This is an expected state of affairs in the chronic period of a mild head injury. ${ }^{4}$ All patients passed a screen for malingering, but they were significantly different in their recognition memory performance on the list learning task. Delayed list recognition is considerably easier than free recall, and poor performance on this task has been described as reflective of malingered cognitive performance on similar paradigms. ${ }^{49}$ Although the average recognition performance was higher than that thought to be reflective of malingering, ${ }^{49}$ it may be possible that some patients were not exerting full effort. However, accuracy and reaction time during the working memory task were no different between patients and controls during the memory and perception conditions

\section{Conclusions}

This study provides potentially useful information for future work. During the resting state, normalised regional cerebral glucose metabolism was similar between patients and controls, but differences emerged in rCBF increases during a spatial working memory task in the inferior right frontal gyrus. Post hoc analysis of this area in the resting state study did not differentiate the groups. In simplistic terms, it is likely that during a more passive state the brain is not using resources required in accomplishing a specific cognitive task.

Mesulam's model of attention ${ }^{50}$ comprises two major operations: the first is a matrix or state function, which serves as an overall information regulator, rendering the person vigilant and ready to act. This is related to the concept of tonic attention and is associated with neural mechanisms in the reticular activating system. The second component is the vector or channel function, which regulates the direction and target of attention. This is similar to selective attention and is associated with neocortical function. Based on Mesulam's attention model, ${ }^{50}$ the resting state paradigm would be considered the "matrix" component of attention, and activation during the spatial working memory task in the current study would be associated with the "vector" component of attention. Therefore, differences between healthy and mildly traumatised brains may not be discernible in resting cerebral metabolism, as cortical tone is not affected postacutely. It is only with the presence of external demands (spatial working memory task) that this mild injury becomes apparent. Hence, this may imply that FDG-PET in the resting state may not be very useful in detecting mild persistent brain injuries ${ }^{15}{ }^{16}$; an activation task may be more promising in this regard.

On the other hand, it also remains to be determined how these functional changes relate to clinical outcome. Given that the vast majority of patients recover well from mild traumatic injuries, ${ }^{4}$ the validity of any change in brain function needs to be interpreted in terms of its impact on daily life. Were these findings present in patients who recover well from injury, and who do not complain of chronic symptoms, then other mediating factors would need to be sought. Moreover, it is also quite possible that there could be functional changes in how a brain accomplishes a specific cognitive goal, even in the absence of chronic neuronal injury. For example, it was clear that these patients were preoccupied with several persistent symptoms. This preoccupation and subjective discomfort could itself induce changes in cerebral perfusion patterns during task performance. Thus we are cautious in concluding that these changes reflect persistent neuropathological change.

In summary, this study did not reveal significant differences in resting FDG uptake between groups of mildly head injured patients with chronic post-concussion symptoms. Minor differences in rCBF did, however, emerge between groups during a visuospatial working memory task. The specificity and clinical relevance of these differences remains to be established.

\section{ACKNOWLEDGEMENTS}

This project was supported by the Physiologic Imaging Research Center of the Indiana University School of Medicine, the American Psychological Association Division 40 and American Psychological Foundation (Henry Hécaen neuropsychology scholarship), and the American Psychological Association Science Directorate (dissertation research award). We would like to thank Mark Lowe PhD, Mario Dzemidzic PhD, and the staff of the Positron Emission Tomography Center; Julie Stout PhD of the Department of Psychology, Indiana University; Jovier Evans PhD, Robert Glueckauf PhD, Jeffery Rasmussen PhD, Kriscinda Marks PhD, Beth Mauer MS, and Michael Turner MD of the Indianapolis Neurosurgical Group for their help and support. 


\section{Authors' affiliations}

S H A Chen, P S Fastenau, Department of Psychology, Indiana University - Purdue University Indianapolis (IUPUI), Indianapolis, Indiana, USA

D A Kareken, Department of Neurology, Indiana University School of Medicine, Indianapolis

G D Hutchins, Departments of Radiology, Indiana University School of Medicine, Indianapolis

L E Trexler, Center of Neuropsychological Rehabilitation, Indianapolis

Competing interests: none declared

\section{REFERENCES}

1 Long CJ, Novack TA. Postconcussion symptoms after head trauma: interpretation and treatment. South Med J 1986;79:728-32.

2 Alexander MP. Mild traumatic brain injury: pathophysiology, natural history, and clinical management. Neurology 1995:45:1253-60.

3 Levin HS, Mattis S, Ruff RM, et al. Neurobehavioral outcome following minor head injury: a three-center study. J Neurosurg 1987;66:234-43.

4 Binder LM. A review of mild head trauma. Part II. Clinical implications. J Clin Exp Neuropsychol 1997;8:323-46.

5 Gray B, Ichise M, Chung DG, et al. Technetium-99m-HMPAO SPECT in the evaluation of patients with a remote history of traumatic brain injury: a comparison with x-ray computed tomography. J Nucl Med 1992;33:52-8

6 Nedd K, Sfakianakis G, Ganz W, et al. 99m Tc-HMPAO SPECT of the brain in mild to moderate traumatic brain injury patients: compared with CT - a prospective study. Brain Injury 1993:7:469-79.

7 Jacobs $A$, Put $E$, Ingels $M$, et al. Prospective evaluation of technetium-99m-HMPAO SPECT in mild and moderate traumatic brain injury. J Nucl Med 1994;35:942-7.

8 Ichise $M$, Chung DG, Wang $P$, et al. Technetium-99m-HMPAO SPECT, $C T$ and $M R I$ in the evaluation of patients with chronic traumatic brain injury: a correlation with neuropsychological performance. J Nucl Med 1994;35:217-26.

9 Kant R, Smith-Seemiller L, Isaac G, et al. Tc-HMPAO SPECT in persistent post-concussion syndrome after mild head injury: comparison with MRI/CT. Brain Injury 1997:11:115-24.

10 AAN Subcommittee. Assessment of brain SPECT: report of the therapeutics and technology assessment subcommittee of the American Academy of Neurology (special article). Neurology 1996;46:278-85.

11 Humayun MS, Presty SK, Lafrance ND, et al. Local cerebral glucose abnormalities in mild closed head injured patients with cognitive impairments. Nucl Med Commun 1989;10:335-44.

12 Ruff RM, Crouch JA, Troster Al, et al. Selected cases of poor outcome following a minor brain trauma: comparing neuropsychological and positron emission tomography assessment. Brain Injury 1994:8: 197-208.

13 Gross H, Kling A, Henry G, et al. Local cerebral glucose metabolism in patients with long-term behavioral and cognitive deficits following mild traumatic brain injury. J Neuropsychiatry Clin Neurosci 1996;8:324-34.

14 Otte A, Ettlin TM, Nitzsche EU, et al. PET and SPECT in whiplash syndrome: a new approach to a forgotten brain? J Neurol Neurosurg Psychiatry 1997;63:368-72.

15 Bicik I, Radanov BP, Schafer N, et al. PET with 18-fluorodeoxyglucose and hexamethylopropylene amine oxime SPECT in late whiplash syndrome. Neurology 1998:51:345-50.

16 Radanov BP, Bicik I, Dvorak J, et al. Relation between neuropsychological and neuroimaging findings in patients with late whiplash syndrome. J Neurol Neurosurg Psychiatry 1999;66:485-9.

17 McAllister TW, Saykin AJ, Flashman LA, et al. Brain activation during working memory 1 month after mild traumatic brain injury: a functional MRI study. Neurology 1999;53:1300-8

18 Mild Traumatic Brain Injury Committee. Committee of the head injury interdisciplinary special interest group of the American Congress of Rehabilitation Medicine. Definition of mild traumatic brain injury. J Head Trauma Rehabil 1993:8:86-7.

19 American Psychiatric Association. Diagnostic and statistical manual of mental disorders, 4th ed, international version. Washington, DC: American Psychiatric Association, 1994.

20 Hiscock $M$, Hiscock CK. Refining the forced choice method for the detection of malingering. J Clin Exp Neuropsychol 1989;11:967-74.

21 Derogatis LR. Symptom checklist-90-R (SCL-90-R). Minneapolis: National Computer Systems Inc, 1975.
22 Spreen O, Strauss E. A compendium of neuropsychological tests: administration, norms, and commentary, 2nd ed. New York: Oxford University Press, 1998

23 Wechsler D. Wechsler memory scale, 3rd ed. San Antonio: The Psychological Corporation, 1997.

24 Wechsler D. Wechsler adult intelligence scale, 3rd ed. New York: The Psychological Corporation, 1997

25 Brittain JL, La Marche JA, Reeder KP, et al. The effects of age and IQ on paced auditory serial addition task (PASAT) performance. Clin Neuropsychologist 1991;5:163-75.

26 Reitan RM, Wolfson D. The Halstead Reitan neuropsychological test: theory and clinical interpretation. Tucson: Neuropsychological Press, 1993.

27 Conners CK, Multi-Health Systems Staff. Conners' continuous performance test. Toronto: MHS, 1995

28 Delis DC, Kramer JH, Kaplan E, et al. California verbal learning test: adult version. San Antonio: The Psychological Corporation, 1987.

29 Norman MA, Evans JD, Miller SW, et al. Demographically corrected norms for the California verbal learning test. J Clin Exp Neuropsychol (in press).

30 Osterreith PA. Le test de copie d'une figure complex: contribution à l'étude de la perception et de la mémoire. Arch Psychol 1944;30:286-356.

31 Taylor LB. Scoring criteria for the ROCF. In: Spreen O, Strauss E, eds. A compendium of neuropsychological tests: administration, norms, and commentary. New York: Oxford University Press, 1991

32 Lezak MD. Neuropsychological assessment, 3rd ed. New York: Oxford University Press, 1995:432.

33 Trahan DE, Larrabee GJ. Continuous visual memory test. Odessa: Psychological Assessment Resources Inc, 1988.

34 Fastenau PS. Extended complex figure test (ECFT) manual. Los Angeles: Western Psychological Services, 2002.

35 Heaton RK. Wisconsin card sorting test manual. Odessa: Psychological Assessment Resources Inc, 1981

36 Gouvier WD, Cubic B, Jones G, et al. Post-concussion symptoms and daily stress in normal and head-injured college populations. Arch Clin Neuropsychol 1992;7:193-211.

37 Grace J, Stout JC, Malloy PF. Assessing frontal behavioral syndromes: reliability and validity of the frontal lobe personality scale. Assessment 1999;6:269-84

38 Jonides J, Smith EE, Koeppe RA, et al. Spatial working memory in humans as revealed by PET. Nature 1993;363:623-5.

39 Duvernoy HM. The human brain: surface, three-dimensional sectional anatomy and MRI. New York: Springer-Verlag, 1995.

40 Gold S, Arndt S, Johnson D, et al. Factors that influence effect size in ${ }^{15} \mathrm{O}$ PET studies: a meta-analytic review. Neuroimage 1997;5:280-91.

41 Talairach J, Tournoux P. Co-planar stereotaxic atlas of the human brain 3-Dimensional proportional system: an approach to cerebral imaging. New York: Georg Thieme Verlag, 1988.

42 Baxter LR, Schwartz JM, Phelps ME, et al. Reduction of prefrontal cortex glucose metabolism common to three types of depression. Arch Gen Psychiatry 1989:46:243-50.

43 Baxter LRJ, Phelps ME, Mazziota JC, et al. Cerebral metabolic rates for glucose in mood disorders : studies with positron emission tomography and fluorodeoxyglucose F18. Arch Gen Psychiatry 1985;42:441-7.

44 Bench CJ, Friston KJ, Brown RG, et al. The anatomy of melancholia focal abnormalities of cerebral blood flow in major depression. Psychol Med 1992;22:607-15.

45 Dolan FJ, Bench CJ, Brown RG, et al. Regional cerebral blood flow abnormalities in depressed patients with cognitive impairment. J Neurol Neurosurg Psychiatry 1992;55:768-73.

46 Drevets WC, Videen TO, Price JL, et al. A functional anatomical study of unipolar depression. J Neurosci 1992;12:3628-41.

47 Hurwitz TA, Clark C, Murphy E, et al. Regional cerebral glucose metabolism in major depressive disorder. Can J Psychiatry 1990;35:684-8.

48 Martinot JL, Hardy P, Feline A, et al. Left prefrontal glucose hypometabolism in the depressed state: a confirmation. Am J Psychiatry 1990:147:1313-17.

49 Suhr J, Tranel D, Wefel J, et al. Memory performance after head injury: contributions of malingering, litigation status, psychological factors, and medication use. J Clin Exp Neuropsychol 1997;19:500-14

50 Mesulam MM. Attention, confusional states, and neglect. In: Mersulam MM, ed. Principles of behavioral neurology, vol 3. Philadelphia: FA Davis, 1985: 125-68 